\title{
Vốn sinh kế và giải pháp nâng cao thu nhập cho nông hộ trên địa bàn xây dựng nông thôn mới tỉnh Hậu Giang
}

\section{Livelihood assets and solutions for improving households' income in new rural areas of Hau Giang Province}

\author{
Võ Hồng Tú ${ }^{1}$, Nguyễn Thuỳ Trang ${ }^{1 *}$ \\ ${ }^{1}$ Khoa Phát triển Nông thôn, Trường Đại học Cần Thơ, Việt Nam \\ *Tác giả liên hệ, Email: nttrang@ @ctu.edu.vn
}

THÔNG TIN

DOI: $10.46223 / \mathrm{HCMCOUJS}$.

soci.vi.16.2.1899.2021

Ngày nhận: 27/05/2021

Ngày nhận lại: 24/06/2021

Duyệt đăng: 19/07/2021

Tù khóa:

nông thôn mới; sinh kế; sinh kế bền vững

Keywords:

new rural program; livelihood assets; sustainable livelihood

\section{TÓM TÁT}

Xây dựng nông thôn mới là một trong những chương trình trọng điểm với mục tiêu phát triển toàn diện khu vực nông thôn. Hậu Giang là tỉnh đi đầu ở Đồng bằng sông Cửu Long về thực hiện nông thôn mới. Do vậy, nghiên cứu thực hiện điều tra 458 quan sát tại Hậu Giang để tìm hiểu nguồn vốn sinh kế và so sánh sánh nguồn vốn sinh kế ở các nhóm xã có kết quả xây dựng nông thôn mới khác nhau. Kết quả nghiên cứu cho thấy, nhìn chung năm nguồn vốn sinh kế nông hộ ở nhóm xã hoàn thành tốt là cao hơn so với các nhóm xã còn lại. Kết quả hồi quy đa biến cho thấy có 04 yếu tố ảnh hưởng có ý nghĩa và tỷ lệ thuận đến thu nhập nông hộ, gồm diện tích đất của nông hộ, tình hình vốn vay, nhân khẩu trong gia đình và nhóm xã hoàn thành tốt xây dựng nông thôn mới.

ABSTRACT
New rural construction is one of the key programs with the
goal of comprehensive development of rural areas. Hau Giang is
the leading province in the Mekong Delta in implementing the
new rural program. Therefore, the study carried out interviews of
458 observations in Hau Giang to find out the current status of
rural livelihood assets and compare the livelihood assets among
three groups of communes with different levels of the
complement of New Rural criteria. The research results show
that, in general, the five livelihood assets of households in the
well-performed group of communes are much better than the
remaining two groups. The multiple regression shows four factors
affecting the households income significantly and positively,
including farm size, credit access, family size, and the well-
performed communes.

\section{Giới thiệu}

Trong bối cảnh hội nhập kinh tế và sự cạnh tranh của thị trường nông sản giữa các quốc gia sản xuất nông nghiệp, Việt Nam cần có những chính sách cụ thể cho phát triển đồng bộ và toàn diện để nâng cao tính cạnh tranh và khả năng hội nhập của nông nghiệp, nông dân và nông 
thôn. Để góp phần thực hiện công nghiệp hóa và hiện đại hóa khu vực nông thôn, việc cần làm hiện nay là xây dựng một mô hình mới để phát huy các khả năng và nội lực của nông dân. Thực hiện Nghị quyết 26-NQ/TW ngày 05/08/2008 của Hội nghị lần thứ bảy Ban chấp hành Trung ương (2008) về "Nông nghiệp, nông dân và nông thôn" Thủ tướng chính phủ đã ban hành "Chương trình mục tiêu quốc gia về xây dựng Nông Thôn Mới (NTM) giai đoạn 2010 - 2020" theo Quyết định 800/QĐ-TTg ngày 06/04/2010 (Thủ tướng chính phủ, 2010) và được thay thế bởi Quyết định 1600/QĐ-TTg ngày 16/08/2016 (Thủ tướng chính phủ, 2016a). Cùng với đó là các quyết định về "Bộ tiêu chí Quốc gia về nông thôn mới” cũng được ban hành như Quyết định số 491/QĐ-TTg ngày 16/04/2009 (Thủ tướng chính phủ, 2009); Quyết định 1980/QĐ-TTg ngày 17/10/2016 (Thủ tướng chính phủ, 2016b). Mục tiêu của chương trình xây dựng NTM là một khu vực nông thôn có cơ cấu kinh tế và hình thức tổ chức sản xuất phù hợp, sự gắn kết chặt chẽ giữa nông nghiệp với công nghiệp, hạ tầng kinh tế - xã hội nông thôn hiện đại, gắn phát triển nông thôn với đô thị; môi trường được quan tâm bảo vệ; an ninh trật tự được giữ vững; mức sống người dân nông thôn ngày càng nâng cao.

Hậu Giang là là tỉnh đi đầu trong thực hiện xây dựng NTM ở vùng Đồng Bằng Sông Cửu Long (ĐBSCL) và thị xã Ngã Bảy (nay là thành phố Ngã Bảy) là đơn vị cấp huyện đầu tiên của khu vực được Thủ tướng Chính phủ công nhận đạt chuẩn NTM. Nhờ sự đầu tư có trọng tâm, trọng điểm, sự tham gia đóng góp, ủng hộ rộng rãi của doanh nghiệp, người dân và cả hệ thống chính trị nên kết cấu hạ tầng nông thôn của tỉnh Hậu Giang ngày càng hiện đại, hạ tầng phục vụ sản xuất, sinh hoạt, $\mathrm{y}$ tế, giáo dục, môi trường được đầu tư khang trang. Sau 10 năm thực hiện chương trình xây dựng NTM, đến nay toàn tỉnh có hơn $60 \%$ số xã đã hoàn thành mục tiêu. Đến cuối năm 2020, Hậu Giang đã có 32 xã trong tổng số 51 xã và 01 huyện, 02 thành phố được công nhận đạt chuẩn NTM (Văn phòng điều phối NTM tỉnh Hậu Giang, 2020). Tuy là tỉnh dẫn đầu khu vực ĐBSCL về xây dựng NTM, nhưng đời sống vật chất và tinh thần của một bộ phận người dân nông thôn còn gặp nhiều khó khăn, chất lượng cuộc sống của người dân chưa được cải thiện, nhiều tiêu chí thực hiện còn bất cập chưa phù hợp với tình hình thực tế của địa phương. Nhận thấy được tính cấp bách của vấn đề nên đề tài nghiên cứu "Mối liên hệ giữa nguồn vốn sinh kế của nông hộ và kết quả xây dựng NTM ở Hậu Giang" được thực hiện nhằm tìm ra mối liên hệ giữa nguồn vốn sinh kế của người dân với kết quả xây dựng NTM ở tỉnh Hậu Giang, từ đó đề xuất các giải pháp góp phần thực hiện hiệu quả và bền vững chương trình xây dựng nông thôn mới trên địa bàn tỉnh và góp phần nâng cao đời sống người dân.

\section{Cơ sở lý thuyết và phương pháp nghiên cứu}

\subsection{Tổng quan tài liệu và cơ sở lý thuyết}

Sinh kế không đơn thuần là kế sinh nhai và nơi ở mà nội hàm của thuật ngữ này còn liên quan đến khả năng tiếp cận thông tin, quyền sở hữu, kỹ năng và các mối quan hệ giữa nguồn vốn sinh kế và các hợp phần khác trong khung sinh kế bền vững. Tài sản sinh kế là nguồn lực cơ bản của một tác nhân nhằm thực hiện, tái sản xuất, ứng phó hoặc thay đổi các nguyên tắc để chi phối sự kiểm soát, sử dụng chuyển đổi các nguồn lực (Bebbington, 1999). Tài sản sinh kế gồm năm nguồn vốn khác nhau, cụ thể là vốn con người, vốn tự nhiên, vốn xã hội, vốn vật chất, vốn tài chính, trong đó mỗi loại tài sản được quyết định bởi nhiều tiêu chí nhỏ (Carney, 1998; Chambers \& Conway, 1992). Các nguồn vốn này có mối liên hệ và tác động qua lại cũng như hỗ trợ lẫn nhau, trong đó nguồn vốn con người có vai trò quan trọng trong thúc đầy việc sử dụng các loại tài sản sinh kế khác. Sinh kế được xem là bền vững khi khi nó có thể ứng phó được với các tác động ngắn hạn (shocks) và thích nghi với các ảnh hưởng trong dài hạn hay nói cách khác là các sinh kế có thể phục hồi (resilience), duy trì (maintainance) và tăng cường (enhance) được những khả năng và nguồn lực (assets) hiện tại cũng như tương lai, mà không ảnh hưởng đến nguồn tài nguyên thiên nhiên (Carney, 1998). Khái niệm này được phát triển dựa trên kết quả nghiên cứu 
của Sen (1981) về “Quyền được lựa chọn và thực hiện và khả năng của con người” và Chambers và Conway (1992) về sinh kế. Sinh kế bền vững dựa vào nguyên tắc tiếp cận lấy con người làm trung tâm (Ashley \& Carney, 1999). Như vậy, khung sinh kế bền vững là một công cụ nhằm giúp tìm hiểu và phân tích một cách toàn diện liên quan đến sinh kế. Khung sinh kế giúp chỉ ra những khía cạnh quan trọng và mô tả sự liên hệ giữa chúng (vốn sinh kế và các hợp phần trong khung sinh kế), mô tả được các ảnh hưởng, tiến trình và nhấn mạnh sự đa dạng tương tác giữa các nhân tố/hợp phần khác nhau có ảnh hưởng đến sinh kế. Theo Carney (2003) khung sinh kế được thiết kế như Hình 1 sau:

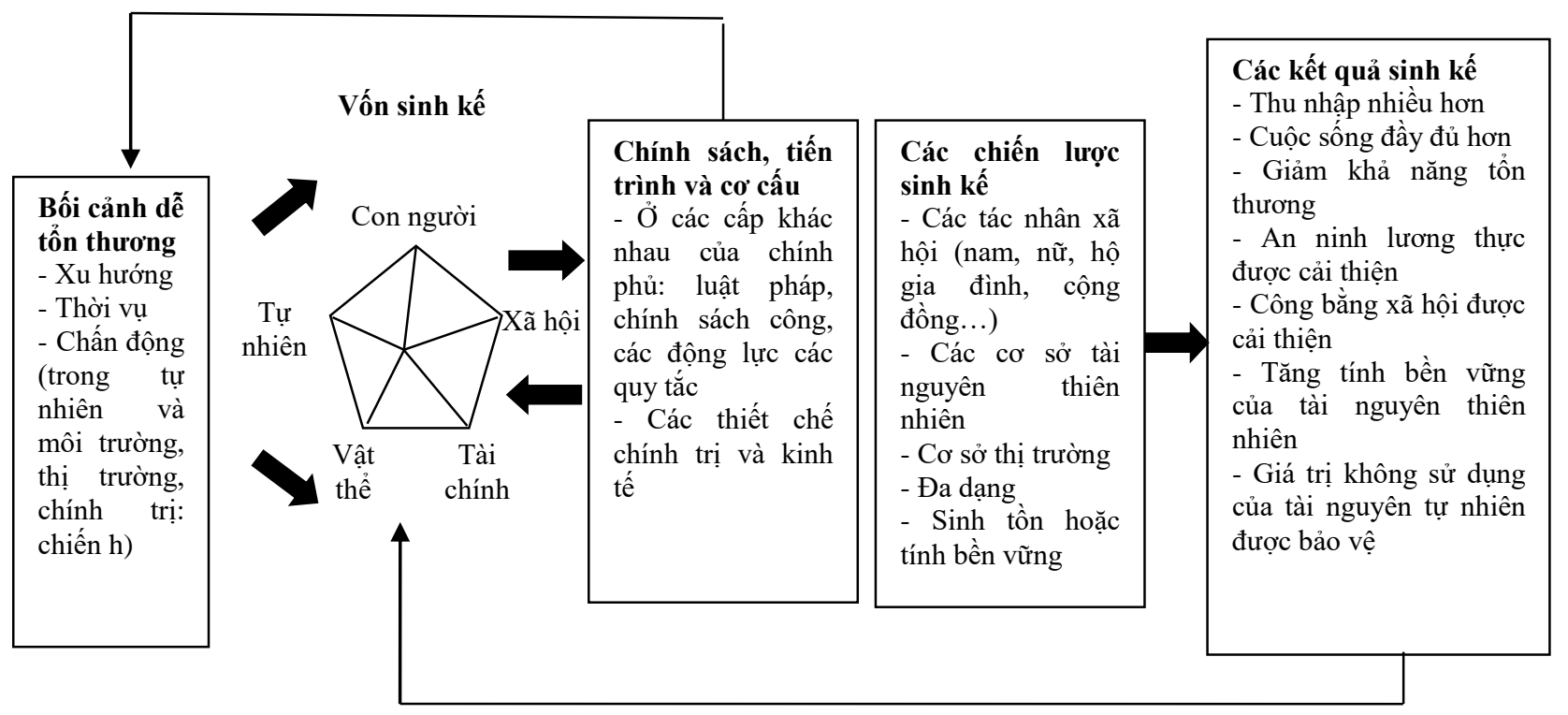

Hình 1. Khung phân tich sinh kế bền vững

Nguồn: Carney (2003)

Nhiều công trình nghiên cứu ngoài nước về sinh kế mặc dù có cách tiếp cận khác nhau, từ các lĩnh vực khác nhau như xã hội học, kinh tế học, ... nhưng chủ yếu vẫn dựa vào 05 nguồn vốn cơ bản: vốn con người, vốn tài chính, vốn tự nhiên, vốn xã hội, vốn vật chất, (Ashley \& Carney, 1999; Carney, 2003; Chambers \& Conway, 1992; Morse \& McNamara, 2013; Scoones 1998; Solesbury, 2003; Small, 2007; Twigg, 2007).

Vận dụng khung sinh kế bền vững của các nhà nghiên cứu trên thế giới, đặc biệt là khung sinh kế bền vững của Cơ quan phát triển Quốc tế của Anh (DFID) (Carney, 2003), nhiều nhà nghiên cứu trong nước đã thực hiện nhiều công trình nghiên cứu về sinh kế, biến đổi sinh kế do tác động của quá trình công nghiệp hóa (industrialization), di cư (migration), tái định cư (resettlement), phát triển du lịch (Dao, 2015; Do, 2017; Hoang \& Pham, 2012; H. V. Nguyen, 2012; B. V. Tran, 2015).

Nghiên cứu này ứng dụng khung phân tích sinh kế bền vững của DFID (Carney, 2003) về 05 nguồn vốn sinh kế dưới tác động của chương trình xây dựng NTM để xem xét mối quan hệ giữa nguồn vốn sinh kế của người dân tại địa bàn nghiên cứu với kết quả đạt được của chương trình NTM nhằm góp phần đề xuất giải pháp phát triển toàn diện bộ mặt nông thôn nói chung và nâng cao mức sống của người dân nói riêng.

\subsection{Phương pháp nghiên cúu}

\subsubsection{Phương pháp chọn vùng và mẫu nghiên cúu}

Theo số liệu thống kê từ Văn phòng điều phối NTM tỉnh Hậu Giang (2019), tính đến tháng 06/2018 toàn tỉnh không có xã nào đạt dưới 05 tiêu chí, nhóm xã đạt từ 15 - 18 tiêu chí chỉ 
có 01 xã, phần lớn tập trung ở nhóm từ 10 - 14 tiêu chí (25 xã), xã đạt từ 05 - 09 tiêu chí có 04 xã.

Từ thực trạng trên, để tạo cở sở cho so sánh, nghiên cứu tiến hành chọn 03 nhóm xã có mức độ hoàn thành khác nhau: Nhóm 1 (hoàn thành tốt, hoàn thành trên 15 tiêu chí). Nhóm 2 (hoàn thành khá, hoàn thành từ 10 - 14 tiêu chí), Nhóm 3 (hoàn thành trung bình, dưới 10 tiêu chí).

\section{Bảng 1}

Địa bàn nghiên cứu

\begin{tabular}{lllc}
\hline \multicolumn{1}{c}{ Nhóm xã } & \multicolumn{1}{c}{ Huyện } & \multicolumn{1}{c}{ Xã } & \multicolumn{1}{c}{$\begin{array}{c}\text { Số tiêu chí } \\
\text { hoàn thành }\end{array}$} \\
\hline \multirow{3}{*}{ Hoàn thành tốt } & Ngã Bảy & Đại Thành & 19 \\
& Châu Thành A & Trường Long Tây & 19 \\
Hoàn thành khá & Châu Thành & Đông Phước A & 16 \\
& Tx. Long Mỹ & Long Phú & 13 \\
Hoàn thành thấp & Vị Thủy & Vĩnh Trung & 10 \\
& Phụng Hiệp & Hòa An & 9 \\
\hline
\end{tabular}

Nguồn: Văn phòng điều phối NTM tỉnh Hậu Giang (2019)

Nghiên cứu được thực hiện trên 07 xã (Đại Thành, Trường Long Tây, Vĩnh Viễn $\mathrm{A}$, Đông Phước A, Vĩnh Trung, Long Phú và Hòa An) của 07 huyện (Ngã Bảy, Châu Thành $A$, thị xã Long Mỹ, Vị Thủy, Phụng Hiệp, Long Mỹ) của tỉnh Hậu Giang. Đối tượng nghiên cứu là những hộ dân đang sinh sống trên địa bàn 07 xã. Đề tài sử dụng phương pháp phỏng vấn ngẫu nhiên theo hình thức bước nhảy, cụ thể là chọn 03 tuyến xã có điều kiện kinh tế giàu, khá và trung bình theo sự hướng dẫn của cán bộ địa phương. Trên một tuyến đường, nghiên cứu tiến hành chọn 01 hộ và sau đó bỏ 01 hộ và phỏng vấn hộ tiếp theo, tiến trình thực hiện được lặp lại cho đến khi đủ số quan sát theo yêu cầu. Tổng số quan sát là 458.

\section{Bảng 2}

Thống kê hộ khảo sát trong xã

\begin{tabular}{lcc}
\hline \multicolumn{1}{c}{ Xã } & Tần số (hộ) & Tỷ lệ \\
\hline Đại Thành & 41 & 8.95 \\
Vĩnh Viễn A & 71 & 15.50 \\
Đông Phước A & 53 & 11.57 \\
Long Phú & 79 & 17.25 \\
Hòa An & 87 & 19 \\
Vĩnh Trung & 77 & 16.81 \\
Trường Long Tây & 50 & 10.92 \\
\hline \multicolumn{1}{c}{ Tổng } & $\mathbf{4 5 8}$ & $\mathbf{1 0 0}$ \\
\hline
\end{tabular}

Nguồn: Số liệu điều tra trong (2019), $\mathrm{n}=458$

\subsubsection{Phuơng pháp phân tích số liệu}

Bước 1: Nghiên cứu sử dụng phương pháp thống kê mô tả để mô tả bức tranh tổng quát về thực trạng sinh kế của nông hộ tại các địa bàn nghiên cứu và thực trạng thu nhập khi có kết quả xây dựng NTM;

Bước 2: Để tìm mối liên hệ giữa các vốn sinh kế và kết quả của quá trình xây dựng NTM ở tỉnh Hậu Giang, nghiên cứu sử dụng phân tích bảng chéo (Cross-tabulation); 
Bước 3: Do kết quả đầu ra mong đợi cuối cùng của các hoạt động sinh kế mà nông hộ đặt trọng tâm nhất là thu nhập nên để phân tích các yếu tổ ảnh hưởng đến thu nhập của người dân tại tỉnh Hậu Giang, nghiên cứu sử dụng phân tích hồi quy đa biến: Phương trình được viết dưới dạng như sau:

$$
Y_{i}=\beta_{0}+\beta_{1} X_{1}+\beta_{2} X_{2}+\beta_{3} X_{3}+\beta_{4} X_{4} \ldots+\beta_{i} X_{i}+\varepsilon_{i}
$$

$Y_{\mathrm{i}}$ : Thu nhập của nông hộ; $\beta_{\mathrm{i}}$ : Các tham số cần ước lượng trong mô hình; $\mathrm{X}_{i}$ là các biến độc lập trong mô hình hồi quy; $\varepsilon_{i}$ là sai số của mô hình hồi quy có phân phối chuẩn.

Các biến độc lập đưa vào mô hình là các biến đại diện cho 05 nguồn vốn sinh kế và các biến về điều kiện kinh tế xã hội của hộ cũng như mức độ hoàn thành các tiêu chí.

\section{Bảng 3}

Các yếu tố ảnh hưởng đến thu nhâp ở nông hộ tỉnh Hậu Giang

\begin{tabular}{|c|c|c|c|c|}
\hline Tên biến & $\begin{array}{c}\text { Ký } \\
\text { hiệu }\end{array}$ & Mô tả & Nguồn tài liệu & Dấu \\
\hline Diện tích đất & $X_{1}$ & $\mathrm{Ha}$ & $\begin{array}{l}\text { Truong và Dang (2011); Huynh và } \\
\text { Mai (2011) }\end{array}$ & + \\
\hline Tình hình thủy lợi & $X_{8}$ & Thang điểm từ 1 - 10 & $\begin{array}{l}\text { Do thu nhập nông hộ phụ thuộc phần } \\
\text { lớn về sản xuất nông nghiệp, nên } \\
\text { nghiên cứu muốn tìm hiều về nhận } \\
\text { thức của người dân về sự hoàn chỉnh } \\
\text { của hệ thống thuỷ lợi phục vụ cho hệ } \\
\text { thống sản xuất của họ (1 rất chura } \\
\text { hoàn chinh và } 10 \text { là rất hoàn chinh) }\end{array}$ & + \\
\hline Kinh nghiệm & $X_{2}$ & Năm & N. Q. Nguyen và Bui (2011) & - \\
\hline Tuổi chủ hộ & $X_{3}$ & Năm & $\begin{array}{l}\text { N. Q. Nguyen và Bui (2011); T. V. } \\
\text { Vo và Le (2015); T. Q. Tran (2015) }\end{array}$ & - \\
\hline Trình độ & $X_{4}$ & Lớp & $\begin{array}{l}\text { N. Q. Nguyen và Bui (2011); T. V. } \\
\text { Vo và Le (2015); T. Q. Tran (2015) }\end{array}$ & + \\
\hline Nhân khẩu & $X_{5}$ & Người & $\begin{array}{l}\text { N. Q. Nguyen và Bui (2011); T. Q. } \\
\text { Tran (2015) }\end{array}$ & + \\
\hline Giới tính & $X_{6}$ & $1=$ nam; $0=$ nữ & $\begin{array}{l}\text { Truong và Dang (2011); T. Q. Tran } \\
\text { (2015) }\end{array}$ & + \\
\hline Tình hình vay vốn & $X_{7}$ & $\begin{array}{c}1 \text { = có vay vốn } \\
0=\text { không vay vốn }\end{array}$ & $\begin{array}{l}\text { Mai (2016); A. T. T. Vo và Phan } \\
\text { (2010); T. Q. Tran (2015); Nghiem, } \\
\text { Coelli, và Rao (2012) }\end{array}$ & + \\
\hline Hoàn thành tốt & $X_{9}$ & $1=$ tốt $; 0=$ còn lại & $\begin{array}{l}\text { Đây là biến mới mà nhóm nghiên cứu } \\
\text { đưa vào trong trường hợp nghiên cứu }\end{array}$ & + \\
\hline Hoàn thành khá & $X_{10}$ & 1= khá; $0=$ còn lại & $\begin{array}{l}\text { này và xem như biến kiểm soát trong } \\
\text { mô hình, được dung để so sánh sự } \\
\text { khác biệt về thu nhập giữa hai nhóm. }\end{array}$ & + \\
\hline
\end{tabular}

Nguồn: Tác giả tổng hợp

\section{Kết quả nghiên cứu}




\subsubsection{Nguồn vốn con người}

Nguồn vốn con người đóng vai trò quan trọng trong các hoạt động sinh kế nông hộ. Để đánh giá nguồn vốn con người thì phải thông qua các tiêu chí như: tuổi, giới tính, trình độ học vấn, kinh nghiệm sản xuất, số nhân khẩu, tỷ lệ lao động phụ thuộc tuổi trong lao động, ... Qua kết quả phân tích cho thấy tuổi chủ hộ trung bình là 56.22 tuổi, cho thấy tình hình dân số tỉnh Hậu Giang đã chuyển sang bước già hóa, cụ thể là có đến $15.1 \%$ dân số có độ tuổi lớn hơn 60 , tỷ lệ dân số trẻ dưới 24 tuổi là rất thấp, trong khi đó đây là nguồn lực lao động thay thế quan trọng trong tương lai (Hình 2). Độ tuổi trung bình của người dân ở nhóm xã mức độ hoàn thành tốt là 56.19 tuổi, ở mức hoàn thành khá là 54.46 tuổi và ở nhóm xã có mức hoàn thành trung bình (dưới 10 tiêu chí) là 57.89 tuổi. Về giới tính của chủ hộ theo các nhóm xã với mức độ hoàn thành khác nhau như sau: đa phần chủ hộ đều là nam giới ở mức độ hoàn thành tốt (chiếm 82.64\%), ở mức độ hoàn thành khá (chiếm $87.82 \%$ ) và mức độ trung bình (chiếm $84.81 \%$ ). Về trình độ học vấn trong địa bàn nghiên cứu khá thấp, đa phần chủ hộ hoàn thành trình độ cấp 1 và 2 , chiếm hơn $70 \%$, trình độ từ trung cấp trở lên chiếm khoảng $5.36-7.82 \%$. Đa số nhân khẩu từ 04 đến 06 người, chiếm $65.3 \%$, trung bình có 4.29 người/hộ, hộ có số nhân khẩu lớn nhất là 08 người/hộ và nhỏ nhất là 01 người. Về lao động chính thì đa số hộ có số lao động chính từ 02 đến 04 người/hộ, chiếm $68.78 \%$.

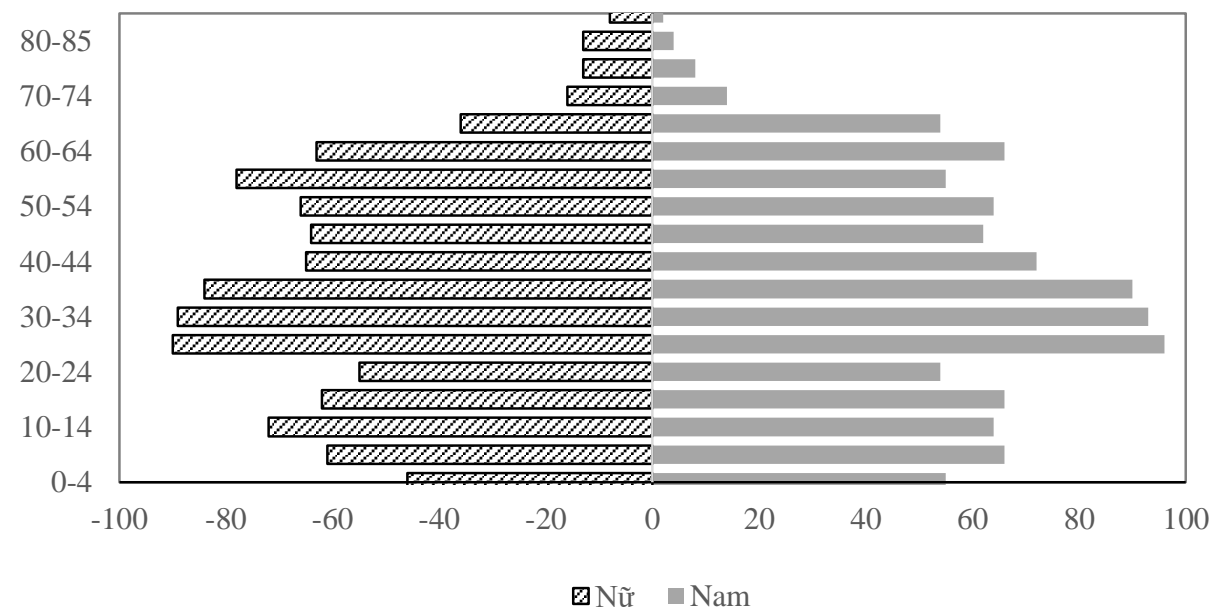

Hình 2. Tháp dân số của tỉnh Hậu Giang

Ghi chú: tháp dân số được tính cho tất cả thành viên hộ

Nguồn: Dựa trên số liệu khảo sát (2019), $\mathrm{n}=458$

\subsubsection{Nguồn vốn tự nhiên}

Nguồn vốn tự nhiên là một trong những yếu tố đặc biệt quan trọng quyết định đến sinh kế của cộng đồng, đặc biệt là người nghèo. Vốn tự nhiên bao gồm tất cả các yếu tố như địa hình, đất đai, khí hậu, điều kiện thủy lợi có ảnh hưởng trực tiếp đến sinh kế hộ. Hậu Giang là tỉnh thuần nông và đất đai là tư liệu quan trọng để sản xuất nông nghiệp và gắn liền với cuộc sống của người dân tại đây. Về diện tích đất canh tác, trung bình mỗi hộ sở hữu khoảng 0.66ha. Tỷ lệ hộ không có đất lại chiếm khá cao, khoảng $22.49 \%$. Đối với nhóm xã có mức độ hoàn thành tốt thì tỷ lệ hộ không có đất chiếm $17.36 \%$, mức độ hoàn thành khá chiếm $22.43 \%$, mức độ hoàn thành trung bình chiếm $27.22 \%$. Sinh kế của các hộ không có đất canh tác chủ yếu dựa vào làm thuê.

Về tình trạng điều kiện thủy lợi, kết quả nghiên cứu cho thấy người dân có đánh giá khá tích cực về sự thay đổi, cụ thể so với trước khi có chương trình xây dựng NTM, có 280 hộ trong tổng 458 hộ khảo sát cho rằng hệ thống thủy lợi thay đổi theo chiều hướng tốt, thông qua việc nạo vét sông, kênh, rạch nên tạo điều kiện lưu thông nước từ sông vào các kênh rạch nội đồng, từ 
đó giúp nông hộ dễ có được nguồn nước tưới phục vụ cho sản xuất.

Qua kết quả phân tích bảng chéo cho thấy với mức ý nghĩa $\alpha=10 \%$ cho thấy có sự khác biệt có ý nghĩa thống kê về tình trạng thủy lợi giữa các nhóm xã có mức độ hoàn thành chương trình NTM khác nhau. Như vậy những xã có mức độ hoàn thành tốt thì người dân đánh giá thuỷ lợi thay đổi tích cực hơn những xã khoàn thành khá và trung bình, đều này cho thấy ở xã hoàn thành tốt đã đầu tư cho các công trình thuỷ lợi nhiều nên đã góp phần thay đổi tích cực điều kiện sống của người dân.

\section{Bảng 4}

Tình trạng điều kiện thủy lợi sau xây dựng NTM

\begin{tabular}{|c|c|c|c|c|c|c|c|c|}
\hline \multirow[t]{2}{*}{ Tình trạng } & \multicolumn{2}{|c|}{ Nhóm Tốt } & \multicolumn{2}{|c|}{ Nhóm Khá } & \multicolumn{2}{|c|}{$\begin{array}{c}\text { Nhóm } \\
\text { Trung bình }\end{array}$} & \multicolumn{2}{|c|}{ Tổng } \\
\hline & Tần số & Tỷ lệ & Tần số & Tỷ lệ & Tần số & Tỷ lệ & Tần số & Tỷ lệ \\
\hline Thay đổi & 98 & 68.05 & 87 & 55.77 & 95 & 60.13 & 280 & 61.14 \\
\hline Không thay đổi & 46 & 31.95 & 69 & 44.23 & 63 & 39.87 & 178 & 38.86 \\
\hline Tổng & 144 & 100 & 156 & 100 & 158 & 100 & 458 & 100 \\
\hline Giá trị $\chi^{2}$ & & & & & $8.25^{*}$ & & & \\
\hline
\end{tabular}

Nguồn: Số liệu khảo sát (2019), $\mathrm{n}=458$

Qua phân tích về nguồn vốn tự nhiên trên địa bàn nghiên cứu những mặt mạnh là điều kiện thủy lợi phục vụ cho hoạt động sản xuất nông nghiệp tương đối hoàn chỉnh và thuận lợi. Tuy nhiên, diện tích đất trung bình tương đối thấp cộng thêm tác động tiêu cực từ tình hình biến đổi khí hậu tại địa bàn nghiên cứu đã đặt ra một thách thức lớn để phát triển kinh tế và nâng cao thu nhập cho người dân.

\subsubsection{Vốn vật chất}

Vốn vật chất trong nghiên cứu này được xem xét bao gồm hai hình thức: vốn vật chất phục vụ cho sinh hoạt và cho hoạt động sản xuất. Phương tiện vật chất phục vụ sinh hoạt rất cần thiết giúp cho đời sống và sinh hoạt của nông hộ. Theo kết quả nghiên cứu trình bày trong Bảng 5 cho thấy nhìn chung, những phương tiện vật chất phục vụ cho nông hộ rất đa dạng và đầy đủ cho cuộc sống tiện nghi, có thể đáp ứng nhu cầu sinh hoạt, vui chơi và giải trí của nông hộ ở ba địa bàn xã có mức độ hoàn thành chương trình NTM khác nhau.

\section{Bảng 5}

Phương tiện vật chất phục vụ sinh hoạt của nông hộ

Đơn vị: số hộ

\begin{tabular}{lcccc}
\hline \multirow{2}{*}{ Phương tiện } & \multirow{2}{*}{ Đơn vị tính } & \multicolumn{3}{c}{ Nhóm xã } \\
\cline { 3 - 5 } & Cái & Nhóm tốt & Nhóm khá & Nhóm trung bình \\
\hline Tivi & Cái & 144 & 156 & 150 \\
Bếp gas & Cái & 142 & 152 & 138 \\
\hline Nồi cơm điện & Cái & 116 & 150 & 137 \\
Tủ lạnh & Cái & 128 & 107 & 105 \\
Quạt gió & & 155 & 139
\end{tabular}




\begin{tabular}{lcccc}
\hline \multirow{2}{*}{ Phương tiện } & \multirow{2}{*}{ Đơn vị tính } & \multicolumn{3}{c}{ Nhóm xã } \\
\cline { 5 - 6 } & & Nhóm tốt & Nhóm khá & Nhóm trung bình \\
\hline Xe gắn máy & Chiếc & 142 & 152 & 145 \\
\hline
\end{tabular}

Nguồn: Số liệu khảo sát (2019), $\mathrm{n}=458$

Phương tiện sản xuất là các thiết bị gắn liền với những hoạt động sản xuất của nông hộ. Hầu hết các nông hộ trên địa bàn nghiên cứu đều làm nông nghiệp nên phương tiện phục vụ sản xuất chủ yếu là máy bơm nước, ghe/xuồng, xe vận chuyển và bình xịt để thuận tiện trong việc đi lại và vận chuyển các phương tiện, vật tư phục vụ hoạt động sản xuất.

\section{Bảng 6}

Phương tiện vật chất phục vụ sản xuất của nông hộ

Đơn vị: số hộ

\begin{tabular}{lcccc}
\hline & Đơn vị & & \multicolumn{3}{c}{ Nhóm xã } \\
\cline { 3 - 5 } Phương tiện & tính & Nhóm tốt & Nhóm khá & Nhóm trung bình \\
\hline Máy bơm nước & Cái & 126 & 118 & 98 \\
Ghe/xuồng & Chiếc & 128 & 116 & 124 \\
Xe vận chuyển & Chiếc & 115 & 126 & 124 \\
Máy cày & chiếc & 2 & 0 & 2 \\
Máy gặt đập & Cái & 4 & 1 & 2 \\
Bình xịt & Cái & 89 & 77 & 58 \\
\hline
\end{tabular}

Nguồn: Số liệu khảo sát (2019), $\mathrm{n}=458$

Bên cạnh đó, kết quả nghiên cứu ở Bảng 7 cũng cho thấy hệ thống hạ tầng giao thông phục vụ nhu cầu vận chuyển, đi lại trong sản xuất và sinh hoạt được người dân đánh giá khá hài lòng, cụ thể có 249 hộ hài lòng chiếm $54.37 \%$ và 155 hộ rất hài lòng, chiếm $33.84 \%$.

\section{Bảng 7}

Đánh giá về hệ thống hạ tầng giao thông

\begin{tabular}{lccc}
\hline \multirow{2}{*}{ Phương tiện } & \multicolumn{3}{c}{ Nhóm xã } \\
\cline { 2 - 4 } & Nhóm tốt & Nhóm khá & Nhóm trung bình \\
\hline Rất hài lòng & 59 & 54 & 42 \\
Hài lòng & 74 & 82 & 93 \\
Không hài lòng & 11 & 20 & 23 \\
\hline Tổng & $\mathbf{1 4 4}$ & $\mathbf{1 5 6}$ & $\mathbf{1 5 8}$ \\
\hline
\end{tabular}

Nguồn: Số liệu khảo sát (2019), $\mathrm{n}=458$

Về hệ thống dịch vụ y tế chăm sóc sức khỏe, kết quả nghiên cứu cho thấy hệ thống này ở các xã được đầu tư khá hoàn thiên. Tại mỗi xã đều có trung tâm y tế được trang bị khá đầy đủ các phương tiện và đội ngũ bác sĩ, nhân viên y tế được đào tạo. Tình hình phục vụ y tế chăm sóc sức khỏe được người dân đánh giá khá cao, chủ yếu ở ở mức hài lòng và rất hài lòng. Kết quả nghiên cứu cũng cho thấy có 394 hộ trong tổng 458 hộ cho rằng việc phục vụ y tế và chăm sóc người dân tốt hơn so với trước, chiếm $86.03 \%$.

\subsubsection{Vốn xã hội}


Nguồn vốn xã hội thể hiện qua việc gia nhập hội, nhóm và các mối quan hệ xã hội khác. Sự tương trợ qua lại giữa cá nhân và cộng đồng được thể hiện ở các khía cạnh tài chính, nhân công, kiến thức và tiếp cận thông tin.

Về tình hình tham gia các hội nhóm của chủ hộ (như hội nông dân, hội phụ nữ, ...) còn khá thấp, chỉ có 95 hộ trong tổng 458 hộ (chiếm tỷ lệ 20.74\%). Xét theo nhóm xã có mức độ hoàn thành xây dựng NTM thì nhóm xã hoàn thành tốt có 43 hộ tham gia (chiếm 29.86\%) và 101 hộ không tham gia (chiếm 70.14\%), nhóm xã hoàn thành khá có 21 hộ tham gia (chiếm 12.18\%) trong tổng 156 hộ, ở nhóm xã có kết quả hoàn thành trung bình có 33 hộ tham gia (chiếm $20.89 \%$ ) trong tổng 158 hộ. Kết quả nghiên cứu cho thấy có mối liên hệ giữa tham gia vào hội nhóm và mức độ hoàn thành xây dựng NTM bằng phân tích bảng chéo ở mức ý nghĩa $\alpha=1 \%$, kết quả này cho thấy ở nhóm xã với kết quả hoàn thành tốt thì tỷ lệ người dân tham gia vào hội nhiều hơn.

\section{Bảng 8}

Tình hình tham gia hội của chủ hộ

\begin{tabular}{|c|c|c|c|c|c|c|c|c|}
\hline \multirow[b]{2}{*}{$\begin{array}{c}\text { Tình hình tham gia } \\
\text { hội }\end{array}$} & \multicolumn{2}{|c|}{ Nhóm Tốt } & \multicolumn{2}{|c|}{ Nhóm Khá } & \multicolumn{2}{|c|}{$\begin{array}{c}\text { Nhóm } \\
\text { Trung bình }\end{array}$} & \multicolumn{2}{|c|}{ Tổng } \\
\hline & Tần số & Tỷ lệ & Tần số & Tỷ lệ & Tần số & Tỷ lệ & Tần số & Tỷ lệ \\
\hline Có & 43 & 29.86 & 19 & 12.18 & 33 & 20.89 & 95 & 20.74 \\
\hline Không & 101 & 70.14 & 137 & 87.82 & 125 & 79.11 & 363 & 79.26 \\
\hline Tổng & 144 & 100 & 156 & 100 & 158 & 100 & 458 & 100 \\
\hline Giá trị $\chi^{2}$ & & & & & $16.45^{* * * *}$ & & & \\
\hline
\end{tabular}

Nguồn: Số liệu khảo sát (2019), $\mathrm{n}=458$

Về quan hệ xã hội thì có 425 hộ trong tổng 458 hộ, chiếm $92.79 \%$ cho rằng mối quan hệ xã hội hiện tại thay đổi so với lúc trước khi xây dựng NTM do điều kiện đi lại thuận tiện hơn, các hoạt động cộng đồng được triển khai nhiều hơn.

\subsubsection{Vốn tài chính}

Nguồn vốn tài chính bao gồm nguồn tiền mặt, tiền gửi ngân hàng, các khoản dễ thanh toán như vàng và vật nuôi. Nông hộ có thể tăng thu nhập của mình bằng cách đa dang hóa các hoạt động sản xuất nông nghiệp và phi nông nghiệp. Những nông hộ có hoạt động sinh kế và nguồn thu nhập đa dạng sẽ góp phần hạn chế tính dễ bị tổn thương trước sự biến động như thiên tai làm giảm năng suất, mất mùa, hay biến động về giá cả thị trường, ... Tính đa dạng nguồn thu nhập tuy không nói lên mức thu nhập nhưng phần nào cho thấy khả năng phân bổ nguồn lực của nông hộ cũng như giảm tính dễ bị tổn thương trước những ảnh hưởng xấu.

- Đa dạng nguồn thu nhập

Để đánh giá được sự đa dạng trong thu nhập của nông hộ, nghiên cứu phỏng vấn trên cùng đối tượng và hỏi trước và sau khi có chương trình xây dựng NTM, sự đa dạng thu nhập của nông hộ có thay đổi đáng kể, cụ thể như sau:

+ Trước NTM: Về tính đa dạng thu nhập trước khi có chương trình NTM (cụ thể là năm 2011) của 458 hộ cho thấy có 40 hộ không có nguồn thu nhập, nhóm hộ này phụ thuộc chính vào 
tiền gửi của con hoặc hỗ trợ từ địa phương, có 336 hộ có một nguồn thu nhập, chiếm 73.36\%, có 79 hộ có từ 02 nguồn, chiếm $17.25 \%$ và có 03 hộ có nguồn thu nhập từ 03 nguồn, chiếm $0.66 \%$;

+ Sau NTM: Sau khi thực hiện xây dựng NTM, sự đa dạng về hoạt động sinh kế của 458 hộ cho thấy có 202 hộ có một nguồn thu nhập, chiếm 44.1\%, giảm khoảng 30\% so với trước NTM; có 242 hộ có nguồn thu nhập từ 02 nguồn, chiếm $52.84 \%$, tăng thêm khoảng $25 \%$ so với trước NTM; có 13 hộ có nguồn thu nhập từ 03 nguồn, chiếm $2.84 \%$ và có 01 hộ có bốn nguồn thu nhập. Từ kết quả này cho thấy thu nhập của người dân có sự thay đổi đáng kể so với trước khi thực hiện xây dựng NTM. Đối với từng nhóm xã có mức độ hoàn thành NTM khác nhau, kết quả nghiên cứu cho thấy nhóm khá và trung bình có sự thay đổi đáng kể về nguồn thu nhập hơn so với nhóm hoàn thành tốt.

\section{Bảng 9}

Thống kê nguồn thu nhập của nông hộ trước và sau NTM

\begin{tabular}{ccccccccc}
\hline \multirow{2}{*}{ Số nguồn } & \multicolumn{2}{c}{ Nhóm tốt } & \multicolumn{2}{c}{ Nhóm khá } & Nhóm trung bình & \multicolumn{2}{c}{ Tổng } \\
\cline { 2 - 8 } & $\begin{array}{c}\text { Trước } \\
\text { NTM }\end{array}$ & $\begin{array}{c}\text { Sau } \\
\text { NTM }\end{array}$ & $\begin{array}{c}\text { Trước } \\
\text { NTM }\end{array}$ & $\begin{array}{c}\text { Sau } \\
\text { NTM }\end{array}$ & $\begin{array}{c}\text { Trước } \\
\text { NTM }\end{array}$ & $\begin{array}{c}\text { Sau } \\
\text { NTM }\end{array}$ & $\begin{array}{c}\text { Trước } \\
\text { NTM }\end{array}$ & $\begin{array}{c}\text { Sau } \\
\text { NTM }\end{array}$ \\
\hline Không nguồn & 8 & 0 & 17 & 0 & 15 & 0 & 40 & 0 \\
Một nguồn & 83 & 61 & 129 & 71 & 124 & 70 & 336 & 202 \\
Hai nguồn & 51 & 80 & 10 & 80 & 18 & 82 & 79 & 242 \\
Ba nguồn & 2 & 3 & 0 & 5 & 1 & 5 & 3 & 13 \\
Bốn nguồn & 0 & 0 & 0 & 0 & 0 & 1 & & 1 \\
\hline
\end{tabular}

Nguồn: Số liệu khảo sát (2019), $\mathrm{n}=458$

- Thu nhập nông hộ

Kết quả nghiên cứu cho thấy tổng thu nhập trung bình của nông hộ giai đoạn trước khi thực hiện xây dựng NTM là 133.64 triệu đồng/hộ/năm, hộ có thu nhập cao nhất là 602 triệu đồng/hộ/năm và thấp nhất là 15 triệu đồng/hộ/năm, từ đó cho thấy khoảng cách giữa hộ có thu nhập cao nhất và hộ có thu thấp nhất là rất lớn. Giai đoạn sau khi thực hiện xây dựng NTM, tổng thu nhập bình quân của nông hộ có xu hướng tăng lên, cụ thể là 168.7 triều đồng/hộ/năm, cao hơn so với trước xây dựng NTM khoảng 35 triệu/hộ/năm. Kết quả nghiên cứu cũng cho thấy khoảng cách về thu nhập giữa hộ cao nhất và thấp nhất cũng có xu hướng tăng lên, cụ thể hộ có thu nhập cao nhất là 906 triệu đồng/ hộ/năm và thấp nhất là 20 triệu đồng/hộ/năm.

Kết quả nghiên cứu cũng cho thấy thu nhập của hộ gia đình từ khi có chương trình xây dựng NTM có sự thay đổi tăng đáng kể, cụ thể tăng 83 hộ có thu nhập trên 100 triệu/hộ/năm. Về tình hình vay vốn tại địa bàn nghiên cứu cho thấy có $58.08 \%$ hộ cho rằng việc tiệp cận vốn vay trở nên dễ dàng hơn.

\section{Bảng 10}

Thu nhập hộ trước và sau NTM 


\begin{tabular}{lcccc} 
& Tần số & Tỷ lệ & Tần số & Tỷ lệ \\
\hline Dưới 100 triêu & 169 & 36.9 & 86 & 18.78 \\
100 - 500 triệu & 284 & 62.01 & 363 & 79.26 \\
Trên 500 triệu & 5 & 1.09 & 9 & 1.96 \\
\hline Tổng & 458 & 100 & 458 & 100 \\
\hline Thu nhập trung bình & & 133.64 & & 168.82 \\
Thu nhập cao nhất & & 602 & 906 \\
Thu nhập thấp nhất & & 15 & & 20 \\
Độ lệch chuẩn & & 84.72 & & 104.47 \\
\hline
\end{tabular}

Nguồn: Số liệu khảo sát (2019), $\mathrm{n}=458$

Để tìm hiểu thêm về sự khác biệt thu nhập theo nhóm xã có mức độ thành khác nhau, Bảng 11 cho thấy thu nhập bình quân nhỏ hơn 25 triệu đồng/người/năm ở cả 03 nhóm xã chiếm tỷ lệ thấp $(2.8 \%$ trong tổng số). Trong khi đó, thu nhập khoảng 25 triệu đến 45 triệu đồng/người/năm ở cả 03 nhóm hộ chiếm tỷ lệ cao nhất $65.5 \%$ và từ trên $45-60$ triệu đồng/người/năm, chiếm $22.05 \%$. Kết quả nghiên cứu cho thấy đa phần đời sống của người dân chưa cao do thu nhập còn nằm trong mức trung bình khá từ 25 - 45 triệu đồng/người/năm.

\section{Bảng 11}

Phân nhóm thu nhập theo các nhóm xã hoàn thành NTM

\begin{tabular}{lcccc}
\hline $\begin{array}{c}\text { Thu nhập } \\
\text { (Triệu/người/năm) }\end{array}$ & $\begin{array}{c}\text { Hoàn thành } \\
\text { tốt }\end{array}$ & $\begin{array}{c}\text { Hoàn thành } \\
\text { khá }\end{array}$ & $\begin{array}{c}\text { Hoàn thành } \\
\text { trung bình }\end{array}$ & Tổng \\
\hline Nhỏ hơn 25 triệu & 1 & 4 & 8 & $\mathbf{1 3}$ \\
Từ $>25$ triệu đến 45 triệu & 82 & 103 & 115 & $\mathbf{3 0 0}$ \\
Trên $>45$ triệu đến 60 triệu & 41 & 33 & 27 & $\mathbf{1 0 1}$ \\
Trên 60 triệu & 20 & 16 & 8 & $\mathbf{4 4}$ \\
\hline Tổng & $\mathbf{1 4 4}$ & $\mathbf{1 5 6}$ & $\mathbf{1 5 8}$ & $\mathbf{4 5 8}$ \\
\hline
\end{tabular}

Nguồn: Kết quả khảo sát (2019), $\mathrm{n}=458$

Từ kết quả phân tích cũng cho thấy, thu nhập bình quân là 38.13 triệu đồng/người/năm. Trong đó, những hộ gia đình có mức thu nhập bình quân cao nhất khoảng 150 triệu đồng và mức thu nhập thấp nhất khoảng 11.6 triệu đồng.

\subsection{Các yếu tố ảnh hưởng đến thu nhập của nông hộ}

Nghiên cứu sẽ tìm hiểu các yếu tố về điều kiện kinh tế xã hội, đặc điểm hộ và mức độ hoàn thành kết quả NTM có ảnh hưởng đến thu nhập nông hộ. Thu nhập được nâng cao và ổn định sẽ góp phần nâng cao các nguồn vốn sinh kế khác, chẳng hạn như đối với vốn vật chất, thu nhập góp phần tăng cường nguồn vốn vật chất thông qua việc mua sắm thêm các phương tiện sản xuất, ... thu nhập góp phần tăng vốn tự nhiên qua việc mua thêm đất đai để thực hiện các hoạt động sản xuất nông nghiệp, và góp phần tăng các nguồn vốn xã hội qua việc hợp tác sản xuất giữa mọi người với nhau tăng thêm các mối quan hệ xã hội giúp ích cho việc tạo dựng sinh kế cho họ và thu nhập cũng sẽ góp phần làm tăng nguồn vốn con người qua việc tiếp cận với giáo dục.

Để xác định và sử dụng kết quả từ mô hình hồi quy trong đề xuất giải pháp, nghiên cứu đã thực hiện kiểm định các sai phạm trong mô hình hồi quy như đa cộng tuyến và phương sai sai 
số thay đổi. Kết quả nghiên cứu cho thấy, mô hình hồi quy không có hiện tượng phương sai sai số thay đổi với giá trị $\chi^{2}=1.25$ (chấp nhận giả thuyết $\mathrm{H}_{0}=$ phương sai không thay đổi) và kết quả từ ma trận tương quan cho thấy không có mối quan hệ tuyến tính nào giữa các cặp biến độc lập trong mô hình hồi quy (với tất cả $\mathrm{r}<0.4$ ). Như vậy, mô hình hồi quy có thể được sử dụng để giải thích các yếu tố ảnh hưởng đến thu nhập nông hộ.

Kết quả hồi quy thể hiện mối quan hệ giữa thu nhập và các yếu tố về đặc điểm hộ cũng như điều kiện kinh tế xã hội nông hộ được trình bày ở Bảng 12 sau:

\section{Bảng 12}

Kết quả phân tích hồi qui về các yếu tố sinh kế ảnh hưởng đến thu nhập

\begin{tabular}{lccc}
\multicolumn{1}{c}{ Biến } & Hệ số hồi qui & S.E. & Giá trị t \\
\hline Hằng số (constant) & $-67.80^{* *}$ & 33.38 & -2.03 \\
$X_{1}$ : Diện tích & $24.77 * * *$ & 5.21 & 4.75 \\
$X_{2}$ : Kinh nghiệm & $-0.28 \mathrm{~ns}$ & 0.30 & -0.95 \\
$X_{3}$ : Vốn vay & $7.44^{* * *}$ & 1.83 & 4.07 \\
$X_{4}$ : Tuổi & $0.33 \mathrm{~ns}$ & 0.38 & 0.87 \\
$X_{5}$ : Trình độ & $1.82 \mathrm{~ns}$ & 1.23 & 1.48 \\
$X_{6}$ : Nhân khẩu & $29.48^{* * *}$ & 3.02 & 9.77 \\
$X_{7}$ : Giới tính & $-11.11 \mathrm{~ns}$ & 12.02 & -0.92 \\
$X_{8}$ : Thủy lợi & $2.36 \mathrm{~ns}$ & 1.97 & 1.20 \\
$X_{9}$ : Hoàn thành tốt & $39.27 * * *$ & 10.27 & 3.82 \\
$X_{10}$ : Hoàn thành khá & $14.47 \mathrm{~ns}$ & 9.93 & 1.46 \\
\hline Số quan sát & & & 458 \\
Giá trị F & & & 22.09 \\
Hệ số xác định $\left(\mathrm{R}^{2}\right)$ & & & 0.316 \\
\hline
\end{tabular}

Ghi chú: *, **, ***, và ns: tương ứng với mức ý nghĩa thống kê $10 \%, 5 \%, 1 \%$ và không có ý nghĩa ở mức $10 \%$ Nguồn: Kết quả được tác giả phân tích (2019)

Kết quả phân tích hồi quy ở Bảng 12 cho thấy thu nhập của nông hộ chịu tác động của các yếu tố sau: diện tích đất, vốn vay, nhân khẩu và mức độ hoàn thành tốt chương trình xây dựng NTM.

Biến mức độ hoàn thành tốt có hệ số hồi quy lớn nhất và có ý nghĩa thống kê ở mức $1 \%$, kết quả này cho thấy nông hộ ở nhóm xã hoàn thành tốt có thu nhập cao hơn so với hai nhóm còn lại khoảng 39.27 triệu đồng/năm/hộ. Điều này cho thấy kết quả điều tra đã góp phần khẳng định thu nhập hộ của nhóm xã hoàn thành tốt là cao hơn và khác biệt có ý nghĩa so với hai nhóm xã có mức độ hoàn thành khá và trung bình. Từ số liệu này cho thấy kết quả chương trình xây dựng NTM đã phần nào làm gia tăng thu nhập của nông hộ và việc xây dựng chương trình NTM là hết 
sức cần thiết và cần tiếp tục đẩy mạnh triển khai thực hiện trong thời gian tới. Tuy nhiên, việc duy trì và nâng cấp (NTM nâng cao và kiểu mẫu) kết quả xậy dựng NTM là hết sức cần thiết.

Biến diện tích đất có ảnh hưởng tỷ lệ thuận với thu nhập ở mức ý nghĩa $1 \%$, điều này có thể dễ dàng giải thích là nông hộ ở địa bàn nghiên cứu có hoạt động sinh kế chính là sản xuất nông nghiệp.

Biến tiếp cận vốn vay cũng có ảnh hưởng tỷ lệ thuận với thu nhập ở mức ý nghĩa $1 \%$, kết quả này cho thấy sự cần thiết của các chương trình hỗ trợ tín dụng nông nghiệp. Biến nhân khẩu hộ cũng có ảnh hưởng tỷ lệ thuận đến thu nhập nông hộ ở mức ý nghĩa $1 \%$.

Tóm lại, kết quả nghiên cứu cho thấy ở nhóm xã có mức độ hoàn thành tốt chương trình xây dựng NTM thì thu thập khác biệt có ý nghĩa so với nhóm xã có mức độ hoàn thành khá và trung bình. Nghiên cứu cũng cho thấy những hộ có nhiều đất sản xuất, nhiều lao động và có tiếp cận vốn tín dụng sẽ là tiền đề quan trọng để gia tăng thu nhập cho nông hộ.

\section{Kết luận}

Nghiên cứu đã góp phần đánh giá thực trạng sinh kế của nông hộ và so sánh sự khác biệt về nguồn vốn sinh kế hộ với kết quả xây dựng nông thôn mới cũng như các yếu tố ảnh hưởng đến thu nhập nông hộ tại tỉnh Hậu Giang. Kết quả nghiên cứu cho thấy năm nguồn vốn sinh kế hộ ở nhóm xã có mức độ hoàn thành tốt chương trình NTM tốt hơn so với hai nhóm xã còn lại, cụ thể là hoạt động sinh kế đa dạng hơn, thu nhập cao hơn, nguồn vốn xã hội được mở rộng hơn tuy nhiên tỷ lệ tham gia hội/nhóm còn khá thấp, vốn tự nhiên được cải thiện và vốn vật chất được tăng cường tốt hơn.

Dựa trên kết quả nghiên cứu, đề tài đề xuất một số giải pháp nhằm góp phần nâng cao thu nhập, cải thiện nguồn vốn sinh kế của người dân cũng như thúc đẩy nhanh kết quả thực hiện chương trình xây dựng NTM của người dân trên địa bàn nghiên cứu:

- Kết quả nghiên cứu cho thấy tiếp cận vốn vay có tác động tích cực đến thu nhập nông hộ trên địa bàn nghiên cứu, do vậy nhà nước cần tiếp tục duy trì và thiết kế các chương trình hỗ trợ người dân vay vốn để phục vụ cho hoạt động sản xuất;

- Về nguồn vốn tự nhiên, với diện tích đất nhỏ, đặc biệt còn nhiều hộ không có đất sản xuất, chiếm $22.49 \%$ thì việc tạo thêm việc làm phi nông nghiệp là cần thiết để tận dụng thời gian nông nhàn cho các nhóm đối tượng này ở tất cả các nhóm xã có mức độ hoàn thành chương trình NTM khác nhau. Thêm vào đó, việc liên kết trong sản xuất để có quy mô diện tích lớn hơn nhằm tận dụng lợi thế về quy mô cũng rất cần thiết.

Khi sinh kế của nông hộ địa bàn nghiên cứu còn gắn với sản xuất nông nghiệp, chính quyền địa phương cần chú trọng công tác dự báo và nghiên cứu thị trường để tránh tình trạng được mùa mất giá, tạo điều kiện để nông dân nâng cao chất lượng sản phẩm từ đó nâng cao thu nhập của người dân. Theo vào đó, cần chú trọng phát triển ngành công nghiệp chế biến để góp phần gia tăng giá trị các mặt hàng nông - thủy sản.

\section{LỜI CÁM ƠN}

Nhóm tác giả xin chân thành cảm ơn Ủy ban nhân dân tỉnh Hậu Giang và Sở Khoa học và Công nghệ tỉnh Hậu Giang đã cấp kinh phí cho nhóm nghiên cứu thực hiện đề tài này.

Nghiên cứu không có mâu thuẫn về lợi ích với bất kỳ cá nhân và tổ chức nào trong quá trình thực hiện đề tài nghiên cứu này. 


\section{Tài liệu tham khảo}

Ashley, C., \& Carney, D. (1999). Sustainable livelihoods: Lessons from early experience. London, UK: Department for International Development.

Ban chấp hành Trung ương. (2008). Nghị quyết 26-NQ/TW ngày 05/08/2008, Hội nghị lần thú bảy Ban chấp hành Trung ương Khóa X về nông nghiệp, nông dân, nông thôn [Resolution 26-NQ/TW dated August 5, 2008, the Seventh Conference of the 10th Central Committee on agriculture, farmers and rural areas]. Retrieved May 10, 2021, from https://tulieuvankien.dangcongsan.vn/van-kien-tu-lieu-ve-dang/hoi-nghi-bch-trunguong/khoa-x/nghi-quyet-so-26-nqtw-ngay-0582008-hoi-nghi-lan-thu-bay-ban-chap-hanhtrung-uong-dang-khoa-X-ve-nong-nghiep-nong-dan-nong-613

Bebbington, A. (1999). Capitals and capabilities: A framework for analyzing peasant viability, rural livelihoods and poverty. World Development, 27(12), 2021-2044.

Carney, D. (1998). Sustainable rural livelihoods. Nottingham, UK: Russell Press Ltd.

Carney, D. (2003). Sustainable livelihoods approaches: Progress and possibilities for change. London, UK: Department for International Development.

Chambers, R. (1983). Rural development-putting the last first. Harlow, UK: Longman Scientific and Technical.

Chambers, R., \& Conway, G. (1992) Sustainable rural livelihoods: Practical concepts for the 21st century (IDS Discussion Paper, No. 296). Brighton, UK: Institute of Development Studies.

Chambers, R., \& Conway, G. R. (1991). Sustainable rural livelihoods: Practical concepts for the 21st century (IDS Discussion Paper, No. 296). Brighton, UK: Institute of Development Studies.

Dao, T. T. (2015). Biến đổi sinh kế của người Dao di cu tụ do tại huyện Cu M'gar, tỉnh Đắk Lắk [Changes in livelihoods of freely migratory Dao people in Cu M'gar district, Dak Lak province] (Doctoral dissertation). Học Viện Khoa học xã hội, Viện Hàn lâm Khoa học Xã hội Việt Nam, Hà Nội, Việt Nam.

Do, Y. H. (2017). Biến đổi văn hóa mưu sinh của cu dân xã Hưong Son, huyện Mỹ Đức, thành phố Hà Nội trong bối cảnh phát triển du lịch [Changing livelihood culture of residents in Huong Son commune, My Duc district, Hanoi city in the context of tourism development] (Doctoral dissertation). Trường Đại học Văn hóa, Hà Nội, Việt Nam.

Ellis, F. (2000). Rural livelihoods and diversity in developing countries. London, UK: Oxford University Press.

Fillenbaum, G. G., \& Wallman, L. M. (1984). Change in household composition of the elderly: A preliminary investigation. Journal of Gerontology, 39(3), 342-349.

Hoang, C., \& Pham, P. Q. (2012). Diễn ngôn, Chính sách và sụ biến đổi văn hóa - sinh kế tộc ngươi [Discourses, policies and cultural change - ethnic livelihoods]. Hanoi, Vietnam: Viện Nghiên cứu Xã hội, Kinh tế và Môi trường (iSEE).

Huynh, X. T. D., \& Mai, N. V. (2011). Phân tích các yếu tố ảnh hưởng đến thu nhập của các hộ chăn nuôi gia cầm ở Đồng bằng sông Cửu Long [Analysis of determinants of poultryraising household income in the Mekong River Delta]. Tạp chi Khoa hoc Truờng Đại hoc Cần Tho, 17b(2011), 87-96. 
Mai, D. T. H. (2016). Tác động của tài chính vi mô đến thu nhập của hộ nghèo ở Việt Nam [Impact of microfinance on income of poor households in Vietnam]. Tap chi Khoa hoc Đại họ Văn Hiến, 4, 38-44.

Morse, S., \& McNamara, N. (2013). Sustainable livelihood approach: A critique of theory and practice. Netherlands: Springer Science \& Business Media.

Nghiem, S., Coelli, T., \& Rao, P. (2012). Assessing the welfare effects of microfinance in Vietnam: Empirical results from a quasi-experimental survey. Journal of Development Studies, 48(5), 619-632.

Nguyen, H. V. (2012). Nghiên cưu sụ thích ứng với đời sống mới của dân di cu Sơn La [Study on the adaptation to the new life of Son La migrants] (Doctoral dissertation). Học viện Khoa học Xã hội - Viện Khoa học Xã Hội Việt Nam, Hà Nội, Việt Nam.

Nguyen, N. Q., \& Bui, T. V. (2011). Các yếu tố ảnh hưởng đến thu nhập của người dân tộc thiểu số ở Đồng Bằng Sông Cửu Long [Factors influencing the income of minority ethnic groups in the Mekong Delta]. Tạp chi Khoa học Đại học Cần Tho, 18a, 240-250.

Scoones, I. (1998). Sustainable rural livelihoods: A framework for analysis (IDS Working Paper, No. 72). Brighton, UK: Institute of Development Studies.

Scoones, I. (2009). Livelihoods perspectives and rural development. The Journal of Peasant Studies, 36(1), 171-196

Sen, A. (1981). Ingredients of famine analysis: Availability and entitlements. The Quarterly Journal of Economics, 96(3), 433-464.

Small, L. A. (2007). The sustainable rural livelihoods approach: A critical review. Canadian Journal of Development Studies, 28(1), 27-38.

Solesbury, W. (2003). Sustainable livelihoods: A case study of the evolution of DFID policy. London, UK: Overseas Development Institute.

Thủ tướng chính phủ. (2009). Quyết định 491/QĐ-TTg ngày 16 tháng 04 năm 2009 về việc ban hành bộ tiêu chí quốc gia về nông thôn mói [Decision No. 491/QD-TTg of April 16, 2009, on national set of criteria on new rural development]. Retrieved May 10, 2021, from https://thuvienphapluat.vn/van-ban/van-hoa-xa-hoi/quyet-dinh-491-qd-ttg-bo-tieu-chiquoc-gia-nong-thon-moi-87345.aspx?v=d

Thủ tướng chính phủ. (2010). Quyết định 800/QĐ-TTg ngày 04 tháng 06 năm 2010 về phê duyệt chương trình muc tiêu quốc gia về xây dụng nông thôn mới giai đoạn $2010-2020$ [Decision No. 800/QD-TTg of June 04, 2010, approving the national target program on building a new countryside during 2010 - 2020]. Retrieved May 10, 2021, from https://thuvienphapluat.vn/van-ban/Van-hoa-Xa-hoi/Quyet-dinh-800-QD-TTg-phe-duyetchuong-trinh-muc-tieu-quoc-gia-106910.aspx

Thủ tướng chính phủ. (2016a). Quyết định 1600/QĐ-TTg ngày 16 tháng 08 năm 2016 về phê duyệt chuơng trình muc tiêu quốc gia xây dưng nông thôn mới giai đoạn 2016 - 2020 [Decision 1600/QD-TTg dated August 16, 2016 approving the national target program on building new rural areas for the 2016-2020 period]. Retrieved May 10, 2021, from https://thuvienphapluat.vn/van-ban/Van-hoa-Xa-hoi/Quyet-dinh-1600-QD-TTg-chuongtrinh-muc-tieu-quoc-gia-xay-dung-nong-thon-moi-2016-2020-320132.aspx

Thủ tướng chính phủ. (2016b). Quyết định 1980/QĐ-TTg ngày 17 tháng 10 năm 2016 về việc ban hành bộ tiêu chí quốc gia về xã nông thôn mói giai đoạn 2016 - 2020 [Decision 1980/QD-TTg dated October 17, 2016 promulgating the national set of criteria for new 
rural communes for the 2016-2020 period]. Retrieved May 10, 2021, from https://thuvienphapluat.vn/van-ban/Van-hoa-Xa-hoi/Quyet-dinh-1980-QD-TTg-bo-tieuchi-quoc-gia-xa-nong-thon-moi-2016-2020-325989.aspx

Tran, B. V. (2015). Biến đổi sinh kế của cộng đồng người Dao vùng lòng hồ Thủy Điện Tuyên Quang sau tái định cu [Changes in livelihoods of Dao community in Tuyen Quang hydropower reservoir after resettlement]. Hanoi, Vietnam: Quỹ phát triển Khoa học và Công nghệ Quốc gia và Trường Đại học Văn hóa Hà Nội.

Tran, T. Q. (2015). Socio-economic determinants of household income among ethnic minorities in the North-West Mountains, Vietnam. Croatian Economic Survey, 17(1), 139-159.

Truong, L. D., \& Dang, T. T. T. (2011). Ảnh hưởng của tín dụng nhỏ đến thu nhập của nông hộ ở tỉnh Hậu Giang [Impact of microcredit on household income in Hau Giang province]. Tạp chí Khoa hoc đào tạo và Ngân hàng, 111, 20-23.

Twigg, J. (2007). Sustainable livelihoods approaches (Guidance Note 10): Tools for mainstreaming disaster risk reduction series. Switzerland: International Federation of Red Cross and Red Crescent Societies/ProVention Consortium.

Văn phòng điều phối NTM tỉnh Hậu Giang. (2019). Báo cáo kết quả thực hiện Chuơng trình MTQG xây dưng nông thôn mới năm 2018 [Report on the implementation results of the National Target Program on building new rural areas in 2018]. Hau Giang, Vietnam: Ủy ban nhân dân tỉnh Hậu Giang.

Văn phòng điều phối NTM tỉnh Hậu Giang. (2020). Báo cáo tóm tắt kết quả 10 năm thực hiện chuơng trình muc tiêu quốc gia xây dưng nông thôn mói giai đoạn 2010 - 2020 [Report summarizing the results of 10 years of implementation of the national target program on building new rural areas for the period 2010 - 2020]. Hau Giang, Vietnam: Ủy ban nhân dân tỉnh Hậu Giang.

Vo, A. T. T., \& Phan, P. D. M. (2010). Nâng cao hiệu quả chương trình tín dụng ưu đãi hộ nghèo của ngân hàng chính sách xã hội tại thành phố Đà Nẵng [Improving the efficiency of capital aid programme for low income households of Vietnam bank for social policies in Da Nang city]. Tạp chí Khoa học công nghệ - Đại học Đà Nã̃ng, 5, 52-29.

Vo, T. V., \& Le, D. C. (2015). Các yếu tố ảnh hưởng đến kết quả sinh kế của nông hộ ở Đồng Bằng Sông Cửu Long [Driving factors affecting livelihood outcomes of farm households in the Mekong Delta]. Tạp chí Khoa hoc Truoòng Đại học Cần Thơ, 38(2015), 120-129. 


\section{(c) (i) (5)}

Creative Commons Attribution-NonCommercial 4.0 International License. 